\title{
Why not a Stress Test in an Asymptomatic Person? "The World Is Drowning......."
}

\author{
Sonia Mishra' ${ }^{1}$, Ajay Mishra² ${ }^{2}$ Jagdish P Mishra ${ }^{3 *}$ \\ ${ }^{1}$ Thomas Jefferson University, Philadelphia, PA 19107 \\ ${ }^{2}$ Georgetown University, Washington, DC 20057 \\ ${ }^{3}$ Rochester Regional Health Care, United Memorial Medical Center, NY
}

\begin{abstract}
Received: 07 February, 2017; Accepted: 06 March, 2017; Published: 15 March, 2017
*Corresponding author: Jagdish P Mishra, MD, FACC, Rochester Regional Health Care, United Memorial Medical Center, 215 Summit Street, Batavia, NY 14020, Tel no: 585-343-3205; E-mail: jpmish@gmail.com
\end{abstract}

\section{Introduction}

While growing up, I remember someone telling me a poignant story: "Once a teenager was drowning in a river, he started to yell, "Help me; help me, the world is drowning.........."

Well, I will come back to this story at the end of this article...

The really so very pertinent question in Medicine is: Should we do any test when someone is asymptomatic? In Cardiology, the very simple question to be asked is: "Do we need to do a stress test when a person is asymptomatic?"

Whether that person is truly asymptomatic or not is altogether a different kind of question, however most of the guidelines (US, European and others) state not to do a stress test when a person is asymptomatic (Class III Indication).

\section{Case Report}

A 65-year old dentist with history of high blood pressure was seen in the emergency room for uncontrolled hypertension. He said that he knows whenever his blood pressure is high: he feels funny in his head and face and takes 'natural stuff' and other things. He said he hates to take any medications and never likes to see any doctor. Because his symptoms were not improving, he decided to visit the emergency room that day. His BP in ER was in the range of 160-185 systolic and 100-112 diastolic. He was given Norvasc 5 years before but he never took it. He said in ER, "When he feels his BP is high, he exercises or bikes to control his BP or talks to God to fix his blood pressure." His list of medications/'natural stuff' included: Vitamin C, L-Carnitine, B complex, selenium, Magnesium and Fish oil.

His blood pressure (BP) $\mathrm{mmHg}$ was controlled in ER with medications, was placed on Lisinopril $5 \mathrm{mg}$ a day and upon discharge, he was advised to come to see me in cardiac consultation.

When I saw him in my office, his BP mmHg was mildly high (164/97) on Lisinopril. He did not give any history of chest pains, exertional shortness of breath, palpitations, dizziness or syncope. He did not give any history of Diabetes and lipid profile was not known to him. He gave no history of tobacco smoking. There was no family history of premature coronary artery disease (CAD).

He was put on a treadmill in my office. He did not develop any chest pressure or chest pains, however his ECG had started to show markedly extensive abnormalities at low level and therefore the stress test was terminated. It took more than 8 minutes for his ECG changes to normalize.

Because his treadmill ECG changes were surprisingly so abnormal, he was started on a beta-blocker, statin and aspirin along with Lisinopril and a diagnostic coronary angiography was recommended. He was not sure that he would undergo this procedure but agreed to call us back and set it up if willing (Figure 1-3).

In a few days, he called back and agreed to have coronary angiography. In the meantime, without our knowledge, he had undergone a CT coronary angiography on his own which was reported to be markedly abnormal as well: Total coronary

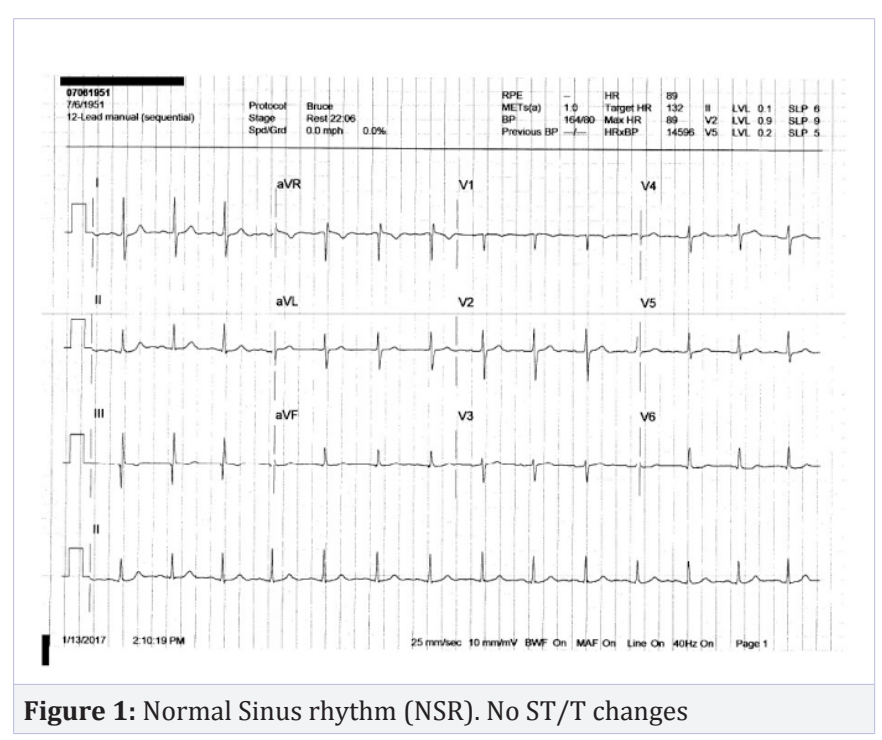


calcium score was 686 and because of heavy calcification, coronary artery anatomy was not well visualized. It was presumably reported to be severe proximal three-vessel CAD and coronary catheterization was recommended once again.

Coronary Catheterization: $60-70 \%$ proximal Right Coronary Artery Disease (RCA), 70\% mid- and 80\% distal RCA disease. Mid circumflex disease $60 \%$, major marginal artery: completely occluded with left to left collaterals. Proximal left anterior descending (LAD) 80\% and distal LAD 50\% disease. Preserved left ventricular systolic function. Severe three-vessel CAD. Coronary artery bypass surgery was recommended. He was not sure that he would like to have bypass surgery but eventually agreed to see a cardiac surgeon.

In summary, we have a case of a 65 -year-old man, to be retired in 2 months dentist with history of hypertension claiming to control by exercise and 'natural stuff' without any other symptoms going on to have a markedly abnormal treadmill stress test at low level of exercise, highly abnormal coronary calcium score and CT angiography and equally markedly abnormal cardiac catheterization report with severe threevessel CAD leading to coronary bypass surgery!

\section{Discussion}

Presently $30-50 \%$ cases of myocardial infarctions may occur

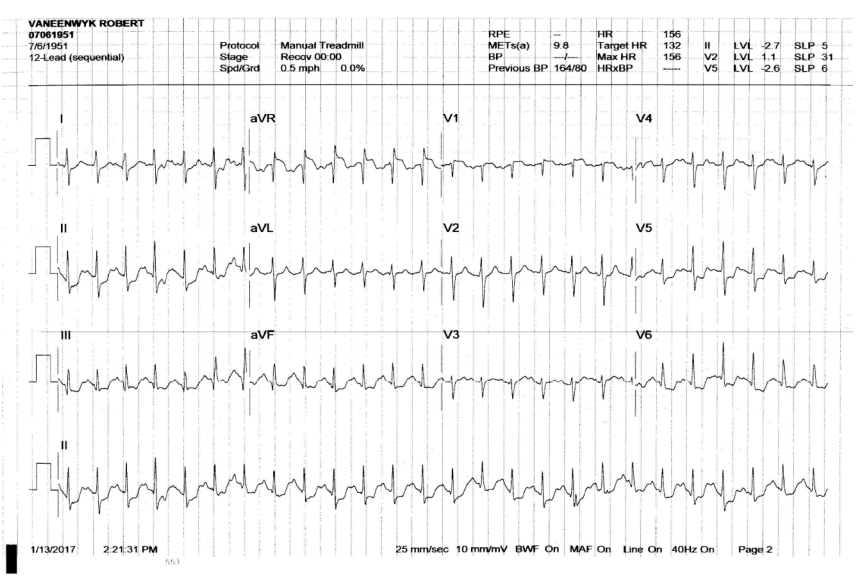

Figure 2: NSR, Marked horizontal/downsloping ST depression in inferolateral leads. Marked ST elevation in aVR. Minimal ST elevation in V1.

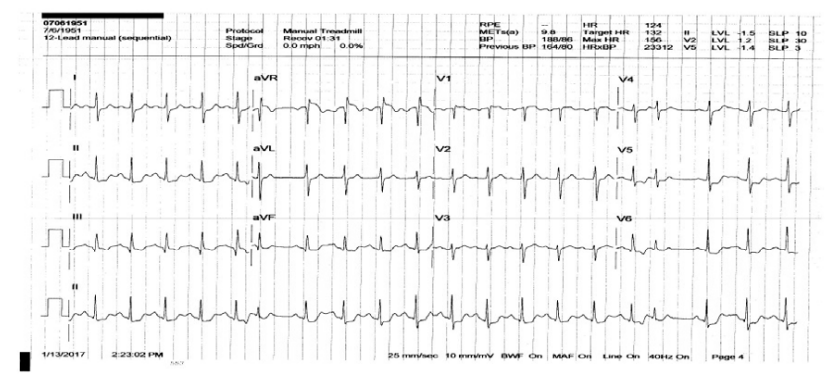

Figure 3: A few minutes into recovery. Those ST changes mentioned in figure 2 have not yet resolved. in individuals not diagnosed previously with CAD, endothelial inflammation and plaque rupture accounting for the acute events. Because of the non-obstructive lesions, stress testing is likely to provide negative results in asymptomatic individuals. Therefore the use of stress testing in asymptomatic persons is controversial [1]. There is not enough data in the literature but the evidence is there showing that asymptomatic individuals do not benefit from active screening for obstructive CAD [2].

However, the burden of CAD/ischemic heart disease is so extensive and the consequences can be so devastating including number one killer, sudden cardiac death that we need to continue to look for better ways to diagnose and treat it even though the search so far looking for ischemia in asymptomatic CAD patients has not shown any favorable outcome [3]. The inappropriate use of stress tests may result in over diagnosis and overtreatment [4]. At least $20 \%$ of health spending in the US may represent unnecessary expenses where the inappropriate use of diagnostic evaluations could contribute to this staggering statistics [5].

An Italian study involving 960 referrals for non-invasive cardiac testing showed that only $33 \%$ referrals were appropriate; the treadmill stress tests had only $27 \%$ appropriate referrals showing the worst outcome among the non-invasive cardiac tests [6]. A Canadian study showed that $42 \%$ of 2,718 patients with suspected CAD had a normal cardiac catheterization, although the majority had a previous positive noninvasive stress test [7]. Likewise a US study with 397,954 patients with mostly elective catheterization showed no obstructive coronary disease, although over $80 \%$ of these patients underwent a previous noninvasive test [8].

However, in spite of all this, it is suggested that exercise stress testing may be recommended among those with the presence of at least one conventional risk factor [9]. Exerciseinduced myocardial ischemia is known to increase the risk of future coronary events not only in patients with CAD but also those with no previously known CAD diagnosis [10].

In addition, another question arises: what about the ST depression in people undergoing stress tests who remain asymptomatic?: This was discussed and answered to some extent in a study published in 2009 [11]. It clearly showed that exerciseinduced ST-depression was a strong predictor of sudden cardiac death particularly in men with coronary risk factors including smoking, dyslipidemia or hypertension even without evident CAD. Moreover ischemic ST depression in the absence of chest pains has been reported to be more common than ST depression with angina in daily life [12]. Some studies have suggested that silent myocardial ischemia is a pathophysiological mechanism through which exercise increases the occurrence of sudden cardiac death [13]. Painless myocardial ischemia could increase the susceptibility to sudden plaque rupture, myocardial infarction and fatal ventricular arrhythmia [14].

Taking this question of being asymptomatic to the next level: how about this situation of having no symptoms in an individual with type II Diabetes? There is plenty of data now strongly associating diabetes with much worse cardiovascular 
events and outcome in the US and other parts of the world. $75 \%$ patients with diabetes eventually die of cardiovascular events- twice the CV mortality than those without diabetes [15]. American Diabetes Association (ADA) recommends screening for CAD even in asymptomatic diabetic patients [16].

While we all understand that we do not recommend a stress test in an 'asymptomatic' person for so many obvious reasons, what do we do in a situation like this one presented in this case report? Moreover, it brings up a very very pertinent question: Societal (guidelines) versus Individual recommendations related to a person's health care!

We do understand that doing any of these tests in an asymptomatic population might lead to further tests, more procedures, harm at times to people in general and above all, huge expenses to the society we live in. On the other hand, I still remember reading in a book or two during my cardiology fellowship training at Hahnemann Hospital in Philadelphia that if we are having less than $30 \%$ or so normal coronary reports, it is possible that we are missing many abnormal cases. That means we are not doing enough cardiac catheterization procedures to make sure not a single person remains undiagnosed! I realize that now we are living in the age of 'perfection' and we need to be doing less and less procedures, however we must not forget that we went to medical school to certainly save lives and not necessarily to 'save' money!

Then, why is it not that we also need to consider the medical approach at an individual level? If a person is paying from his/ her pocket and requests a test, the chances are we will do the test. We all are to worry about the expenses to the society while taking care of our people, but I never hear from anyone ever that the medical cost or the insurance premium is coming down because we are performing less and less tests/procedures. I never hear from any health insurance company that because one person/family has been using much less health services for the last few years and therefore their premium will be reduced for the next few years! Why not? It should be done and that will be an incentive for the family to try to stay healthier.

Talking about individualized medicine, a person is paying the health insurance/premium on a regular basis and we continue to tell him/her that you need no tests or procedures as you have no symptoms. Fine, How about telling the person that you do not have to pay any premiums until you start to have any symptoms and you start to seeing a doctor? Knowing full well that many a times these tests do not help us when we have no symptoms and I agree with that. However for the sake of argument for an individual like this case, who will take the responsibility if that man would have had sudden cardiac death one of these days and we continue to argue: well, too bad, he had no symptoms (while he continued to pay his health premiums religiously)! His family would have lost a loving father, husband and about to retire dentist while we stick to our 'do-no-test-when-no-symptoms approach'!

One can argue why a stress test was performed on him. However let us consider another scenario: I would have seen him and done an ECG and prescribed him another antihypertensive medication and sent him home. I assume everyone would have agreed with my decision. However, if that man would have had massive heart attack next day or had sudden cardiac arrest, how I would have approached his family in the hospital next day? What would I tell them: a stress test was class III/not indicated in his case? And I had to live with the guilt of his death for the rest of my life!

I understand there are many stress tests interpreted as abnormal and further testing will tell us that the person does not have any significant CAD. What is wrong with this approach? Nothing. If he has no CAD, that is the best and most reassuring news. If he has mild/moderate CAD, he can look up those coronary angiography pictures on a computer screen and that could be the most convincing moment for that man to pursue lifestyle modifications to slow down his atherosclerotic disease! That procedural investment could be priceless!

\section{What is Good for the Goose is Good for the Gander}

We learn from population statistics but we do need to practice medicine on an individual level: Or else how will we explain our US ex-president George Bush's cardiac history. He is an avid biker and otherwise asymptomatic but he is having a stress test every year. A few years back, he failed his stress test and that led him to have coronary angiography and stenting of one of his coronary arteries! All along while he had been physically very active and 'asymptomatic'! Why?

Well, if this kind of practice is acceptable for the presidents, CEOs, Directors and other VIPs, then we must assume it had to be a good practice of medicine! So how come it is class III for any ordinary person who is said to be 'asymptomatic!' (What is good for the goose is good for the gander).

Therefore my learning from this case is that we seriously pay attention to the cardiac risk factors and must consider a baseline stress test for most people who seek our opinion regarding the possibility of CAD, still the number one killer in the US and many parts of the world.

That is what I meant by Individual Medical approach. What is good for most people based on the Guidelines might not necessarily be good for an individual! Let the guidelines be the guidelines while I take care of my people, one at a time!

And that brings me up to finish my childhood story that I started to tell you in the beginning of this article: So while the teenager was drowning in the river, he yelled, "Help, save me, the whole world is drowning." A person pulled him out of the river and then asked him, "While in the water, you were yelling that the world was drowning. Now tell me why were you saying that?" The teenager said, "Well, Had I drowned in that river, for me, the whole world would have drowned!"

\section{References}

1. Singh M, Sharma V et al. Stress testing in asymptomatic persons. Medicine update. 2010; 20:275-278

2. Cassel CK, Guest JA. Choosing wisely: Helping physicians and patients make smart decisions about their care. JAMA 2012:307(17): 1801- 
1802. doi: $10.1001 /$ jama.2012.476

3. Harb SC, Cook T, Jaber Wa, Marwick TH. Exercise testing in asymptomatic patients after revascularization: Are outcomes altered? Arch Intern Med. 2012;172(11):854-561

4. Krogsbøll LT, Jørgensen KJ, Grønhøj Larsen C, Gøtzsche PC. General health checks in adults for reducing morbidity and mortality from disease: Cochrane systematic review and meta-analysis. BMJ. 2012;345:e7191. doi: 10.1136/bmj.e7191

5. Berwick DM, Hackbarth AD. Eliminating waste in US healthcare. JAMA 2012:307(14):1513-1516. doi: 10.1001/jama.2012.362

6. Orsini E, Lorenzoni R, Becherini F, Giaconi S, Levantesi D, Lucarini A, et al. Appropriateness of prescription of exercise stress test, echocardiography, Holter monitoring and vascular echography. G Ital Cardiol (Rome). 2007;8(6):359-366

7. Levitt K, Guo H, Wijeysundera HC, Ko DT, Natarajan MK, Feindel CM, et al. Predictors of normal coronaries at coronary angiography. AM Heart J. 2013;166(4):694-700. doi: 10.1016/j.ahj.2013.07.030

8. Patel MR, Peterson ED, Dai D, Brennan JM, Redberg RF, Anderson HV, et al. Low diagnostic yield of elective coronary angiography. $\mathrm{N}$ Engl J Med 2010;362(10): 886-895. doi: 10.1056/NEJMoa0907272

9. Fletcher GF, Balady GJ, Amsterdam EA, Chaitman B, Eckel R, Fleg J, et al. Exercise standards for testing and training: a statement for healthcare professionals from the American Heart Association. Circulation 2001:104(14):1694-1740
10. Detrano R, Gianrossi R, Mulvihill D, Lehmann K, Dubach P, Colombo A, et al. Exercise-induced ST segment depression in the diagnosis of multi-vessel coronary disease: a meta-analysis. J Am Coll Cardiol 1989;14(6):1501-1508

11. Laukkanen JA, Makikallio TH, Rauramaa R, Kurl S. Asymptomatic ST-depression during exercise testing and the risk of sudden cardiac death in middle-aged men: a population-based follow-up study. Eur Heart J. 2009;30(5):558-565. doi: 10.1093/eurheartj/ehn584

12. Deedwania PC, Nelson JR. Pathophysiology of silent myocardial ischemia during daily life. Hemodynamic evaluation by simultaneous ECG and blood pressure monitoring. Circulation. 1990;82(4):12961304

13. Ekelund LG, Suchindran CM, McMahon RP, Heiss G, Leon AS, Romhilt DW, et al. Coronary heart disease morbidity and mortality in hypercholesterolemic men predicted from an exercise test: the Lipid Research Clinics Coronary primary prevention Trial. J Am Coll Cardiol. 1989;14(3):556-563

14. Barsky AJ, Hochstrasser B, Coles NA, Zisfein J, O’Donnell C, Eagle KA. Silent myocardial ischemia. Is the person or the event silent? JAMA 1990;264(9):1132-1135

15. Bonow RO, Bohannon N, Hazzard W. Risk stratification in CAD and special populations. Am J Med. 1996;101(4A):17S-22S

16. American Diabetes Association: consensus development conference on the diagnosis of CAD in people with diabetes. Diabetes Care. 